\title{
Hope And Pediatric Cancer
}

Ákila Macêdo Freire', Hiroê Alencar Braga ${ }^{1}$, Araly Alencar Braga?, Modesto Leite Rolim Neto ${ }^{1}$

\section{Abstract}

Pediatric cancer is rare when compared to the incidence of cases in adults. In Brazil it is the second largest cause of death by disease in children and adolescents. Cancer is a life-altering disease that brings with it fear, disbelief, anger, uncertainty, devastation, at the time it is diagnosed. In childhood cancer, diagnosis extends to the whole family. The diagnosis brings psychological and social changes in family dynamics and needs emotional support, discussion of possible therapies and possible death. Hope comes, bringing with it a meaning in illness, contributing positively to a better adaptation and adherence to treatment and consequently the quality and the prospect of life. Hope has been shown as a positive factor when facing this new reality. However there are few studies dealing with this issue.

\section{Keywords}

Hope, Pediatric Cancer, Palliative Care

Cancer is a leading cause of death worldwide and the total number of cases globally is increasing. New cases of cancer are estimated 15,5 million in 2030[1,2]. Considered a rare disease, cancer Children and Youth (children and adolescents between 0 and 19) corresponds to between $1 \%$ and $3 \%$ of all malignant tumors in most populations. These cancers have mostly short latency periods are more aggressive, rapidly growing, but respond better to treatment and are considered good prognosis. In Brazil, in 2011, there were 2,812 deaths due to cancer in children and adolescents (0-19 years). Neoplasms occupied the second position (7\%) of deaths of children and adolescents in 2011[3].

Diagnosis of cancer often results in fear, uneasiness, devastation, and causes patients to undergo physical, emotional and social changes $[2,4]$. Controlling physical symptoms, providing emotional support, preserving dignity, exploring realistic goals and discussing day-to-day living are important to maintain hope in terminally ill cancer patients $[5,6]$. 
Hope is held to be essential to patient well-being $[7,8]$, to increase patient compliance with recommended treatment $[8,9,10,11]$. Physical, financial and psychological wellbeing, and information and support needs are directly and independently related with hope in people with cancer [12].

The construct of hope has received increasing attention over the last two decades [13, 14, 15]. Hope is a resource of importance to the individual person $[16,17]$. To encourage a sick person to retain hope and avoid despair is an important task for medical personnel [17, 18, 19, 20, 21, 22, 23]. It is not surprising therefore that healthcare workers (including physicians, oncologists, palliative care physicians, nurses, and psychologists) are often urged to consider, maintain, increase, protect, foster, and even to instill hope in a patient $[8,11,24,25,26,27,28$, 29, 30, 31, 32].

However, a limited number of studies have examined the relationships among hope and physical, psychological, and demographic factors in oncology patients [33]. To date, no quantitative studies have investigated the details of how to show specific caring behavior toward family members so that they can maintain hope as well as prepare for the patient's death [6]. This study aims to find out how hope influences in treatment's confidence, outlook on life and facing of death.

Childhood cancer is the leading cause of death from illness in children in high-income countries, although the improvement of therapy for children with cancer has led to a considerable rise of survival rates [34, 35]. From a universally fatal group of diseases up until the 1950's, malignancies in childhood are now reaching 5 year survival rates of nearly $80 \%$ in the developed world $[36,37]$.

Incidence rates of all cancers combined increased significantly among children younger than 20 years from 1975 through 2006, however, the mortality rates for all malignant childhood cancers combined declined by more than 50\% between 1975 and 2006. Among children younger than 1 year of age, 5 year survival rates for all cancers combined in the late 1970s and 1980s exceeded $60 \%$ and reached $78.2 \%$ by $1999-2002$ [38]. And regardless of prognosis or outcome, each diagnosis has a significant impact on the child, their family, and their community. When a child is diagnosed with cancer, the entire family is diagnosed [39].

Childhood cancer is a success story of modern medicine in which effective treatments have been identified for previously untreatable diseases. Pediatric cancer statistics are widely reported with conflicting inferences, creating questions and uncertainty [38]. The child and their entire extended family enter a contract with uncertainty about prognosis, treatment, outcome, and impact. Emotional reactions for the family can include fear, disbelief, anger, anxiety, confusion, hope, concern, and shock $[39,40]$.

An important factor that contributes to this complexity is the enormous impact of childhood cancer on the emotional and social well-being of the developing child and its family [35]. This will have some impact on the long-term survival of children with cancer, but it may significantly affect their quality of life [37]. However, most families will adjust to the trauma, engage their previous coping strategies, and integrate the experience of their child's illness into their life experiences [39, 41]. Important aspects that should be addressed when providing high-quality care for children with cancer include communication and delivery of information in an honest, understandable and cultural appropriate manner [35]. This is essential for supporting the emotional and social well-being of the child with cancer and its family [35, 42, 43]. Despite the high rates of distress, families also demonstrate optimism, resilience, and positive outlook in the face of their child's cancer diagnosis [39]. These traits have been shown to correlate with increased life satisfaction, positive health perception, and decreased anxiety and depression [39, 41, 42]. 
A major near-term medical impact of the genome technology revolution will be the elucidation of mechanisms of cancer pathogenesis, leading to improvements in the diagnosis of cancer and the selection of cancer treatment [46]. The remarkable progress in the treatment of childhood cancer over the past 50 years is often cited as one of the major achievements of modern medicine [37]. From 1975 through 2006, approximately 38,000 childhood cancer-related deaths were averted as a result of treatment advances since 1975 [38]. These technological advances are important for advancing our understanding of malignant neoplasms, therefore, comprehensive genome-based diagnosis of cancer is becoming increasingly crucial for therapeutic decisions [46]. Technological and scientific breakthroughs will surely be needed to yield radically new treatment modalities for those tumor types that fail to respond to current approaches [37].

As the number of childhood cancer survivors continues to grow, general pediatricians, and later, adult primary care physicians will have an increasing role in recognizing these late effects [37].

Palliative care that addresses the multiple physical, emotional, social, and spiritual issues should be provided concomitantly with cancer directed treatment to improve the quality of care [47, 48, 49]. Found that parents and health care professionals make similar considerations during end of life decision-making. Parents also focus on the importance of hope; this factor may loom larger for parents than for health care professionals [50]. Hope, as an inner resource refers to a positive mental construct, an internal source which people going through adversity can draw on in times of crisis or stress [51]. That hope may be important in understanding symptoms and psychological adjustment [15]. Hope has also been defined as a transformative process by which individuals acknowledge the reality of their circumstances, search for meaning, and reappraise their life, which in turn, transforms their hope $[51,52,53]$.
Health care providers involved in the care of children with cancer should establish the prognosis, negotiate goals, guide patients and/or their parents in the process of making difficult medical decisions, provide comfort, enhance quality of life, promote care coordination and continuity, optimize comfort at the end of life, and attend to the needs of bereaved family members [49, 54, 55]. Health care professionals, as a group, tended to regard supportive care alone more positively than did parents, implying that parents and health care professionals generally have different underlying attitudes toward end-of-life treatments [50]. The cancer patients are, on the whole, satisfied with the information concerning the illness and the treatment [17]. Despite the importance of hope for cancer patients and their families, few studies have explored parental hope in the context of caring for children with cancer [51]. Hope has been identified as an important factor for parents to consider in their decision-making in several previous studies $[50,56,57]$. These underlying differences may, in part, contribute to the apparent conflict between professionals and parents when tensions emerge during the palliative phase of care [50].

Propose a care strategy that medical professionals adopt for family members of terminally ill cancer patients so that they will both maintain hope and prepare for the patient's death; this strategy includes the following behavior of the part of professionals: 1) discuss achievable goals and preparations for the future and pace explanations with the family's preparation, 2) be willing to talk about alternative medicine, 3) expend maximum effort to maintain the patient's physical strength, and 4) avoid saying that nothing more can be done for the patient [58].

These findings cumulatively speak to the value of education both for the family and HCPs in understanding these complex processes, and continue clinic based support for families as they navigate this complex and shifting terrain of childhood cancer and its treatment [51]. It must be remembered that 
even the most rational and well tested treatment plans may fail, underscoring the need for comprehensive palliative care to relieve the suffering and improve the quality of life for both the patients and their families [49]. Participants could thus conclude both that hope could enable one to endure adversity in life and that even in adversity, while there is life there is hope [8].

Much research has been done in the experimental area of childhood cancer treatment, achieving significant results in therapeutic possibilities and thus considerable increase in survival rates. However there is no literature data on how much hope can influence the acceptance of the treatment and how children and their parents react to this reality. The research developed describes the perceptions of adults about their own disease (cancer) or report the parents' views on their children's condition. Studies in children on the perception, acceptance and coping cancer are needed.

\section{References}

1. World Health Organization (WHO) (2010). Cancer. Retrieved from http://www.who.int/mediacentre/factsheets/fs297/en/ index. html on 13 May 2010.

2. Kavradim ST, Ozer ZC, Bozcuk H. (2013). Hope in people with cancer: a multivariate analysis from Turkey. J Adv Nurs. 69(5): 1183-1196.

3. (INCA) - Instituto Nacional de Câncer José Alencar Gomes da Silva. (2014). Coordenação de Prevenção e Vigilância Estimativa 2014: Incidência de Câncer no Brasil/Instituto Nacional de Câncer José Alencar Gomes da Silva, Coordenação de Prevenção e Vigilância. Rio de Janeiro: INCA.

4. Mattioli J.L., Repinski R. \& Chappy S.L. (2008) The meaning of hope and social support in patients receiving chemotherapy. Oncology Nursing Forum 35(5), 822-829.

5. Clayton JM, Butow PN, Tattersall MHN, et al. (2005). Fostering coping hope and nurturing hope when discussing the future with terminally ill cancer patients and their caregivers. Cancer 103: $1965 \mathrm{e} 1975$.

6. 30 - Shirado, Akemi et al. (2013). Both Maintaining Hope and Preparing for Death: Effects of Physicians' and Nurses' Behaviors From Bereaved Family Members' Perspectives Journal of Pain and Symptom Management, Volume 45, Issue 5, 848-858.

7. Herth, K. (1995). Engendering hope in the chronically and terminally ill: Nursing interventions. American Journal of Hospice and Palliative Care, 12, 31-39.

8. Eliott JA, Olver IN. (2009). Hope, life, and death: a qualitative analysis of dying cancer patients' talk about hope. Death Stud. 33(7): 609-38

9. Good, M. G. D., Good, B. J., Schaffer, C., \& Lind, S. E. (1990). American oncology and the discourse on hope. Culture, Medicine, and Psychiatry, 14, 59-79.

10. Gordon, D. R. (1990). Embodying illness, embodying cancer. Culture, Medicine, and Psychiatry, 14, 275-297.

11. Gordon, E. J., \& Daugherty, C. K. (2003). "Hitting you over the head": Oncologists' disclosure of prognosis to advanced cancer patients. Bioethics, 17, 142-168.

12. Kavradim ST, Ozer ZC, Bozcuk H. (2013). Hope in people with cancer: a multivariate analysis from Turkey. J Adv Nurs. 69(5): 1183-1196

13. Brouwer D, Meijer RR, Weekers AM, Baneke JJ. (2008). On the dimensionality of the Dispositional Hope Scale. Psychol Assess 20: 310 e315.

14. Snyder CR. (2004). Hope and depression: a light in the darkness. J Soc Clin Psychol 23:347 e 351.

15. Berendes D, Keefe FJ, Somers TJ, Kothadia SM, Porter LS, Cheavens JS. (2010). Hope in the context of lung cancer: relationships of hope to symptoms and psychological distress. Journal of Pain and Symptom Management. 40(2): 174-182. 
16. 13 - Lynch W. (1974). Images of Hope. Imagination as Healer of Hopeless. University Of Notre Dame Press, Notre Dame, Paris, France.

17. 53 - SAEGROV S. \& LORENSEN M. (2006). Cancer patients' opinions concerning post-treatment follow-up. European Journal of Cancer Care 15, 56-64

18. Vaillot M.C. (1970). Living and dying. Hope: the restoration of being. American Journal of Nursing 70, 268-273.

19. Travelbee J. (1971). Interpersonal Aspects of Nursing. T. A. Davis, Philadelphia, PA, USA.

20. Stoner M.J.H. (1982). Hope and cancer patients . PhD Thesis, University Mikrofilm International, University of Colorado Health Center, Co.

21. Nowotny M.L. (1986). Measurement of hope as exhibited by a general adult after a stressfull event. Dissertation Abstracts International 47 (08), 3296 -B (University Microfilms no. 8626494).

22. Herth K.A. (1989). The relationship between level of hope and level of coping response and variables in patients with cancer. Oncology Nursing Forum 16, 67-72.

23. Miller J.F. \& Powers M.J. (1988). Development of an instrument to measure hope. Nursing Research 37, 6-10.

24. Begley, A., \& Blackwood, B. (2000). Truth-telling versus hope: A dilemma in practice. International Journal of Nursing Practice, 6 , 26-31.

25. Cheavens, J. S., Michael, S. T., \& Snyder, C. R. (2005). The correlates of hope: Psychological and physiological benefits. In J. A. Eliott (Ed.), Interdisciplinary perspectives on hope (pp. 119132). New York: Nova Science.

26. Cutcliffe, J. R. (1995). How do nurses inspire and instill hope in terminally ill HIV patients? Journal of Advanced Nursing, 22, 888-895.

27. Dufault, K., \& Martocchio, B. C. (1985). Symposium on compassionate care and the dying experience. Hope: Its spheres and dimensions. Nursing Clinics of North America, 20, 379-391.

28. Duggleby, W. D., Degner, L., Williams, K., Cooper, D., Popkin, D., \& Holtslander, L. (2007). Living with hope: Initial evaluation of a psychosocial hope intervention for older palliative home care patients. Journal of Pain and Symptom Management, 33, 247-257.

29. Kodish, E., \& Post, S. G. (1995). Oncology and hope. Journal of Clinical Oncology, 13, 1817-1822.

30. Orne, M. (1968). On the nature of effective hope. International Journal of Psychiatry, 5, 403-410.

31. Simpson, C. (2002). Hope and feminist care ethics: What is the connection? Canadian Journal of Nursing Research, 34, 81-94.

32. Sokol, D. K. (2006). What is false hope? Journal of Clinical Ethics, 17, 367-368.

33. Duggleby W, Ghosh S, Cooper D, Dwernychuk L. (2013). Hope in newly diagnosed cancer patients. J Pain Symptom Manage. Nov; 46(5):661-70
34. Kellie SJ, Howard SC. (2008). Global child health priorities: what role for paediatric oncologists? Eur J Cancer 44(16): 2388-2396.

35. Knops R. R. G., Hulscher M. E. J. L., Hermens R. P. M. G., Hilbink-Smolders M., Loeffen J. L., Kollen W. J. W., Kaspers G. J. L., Caron H. N., L. C. M. Kremer. (2012). High-quality care for all children with cancer. Ann Oncol 23 (7): 1906-1911 first published online February 8, 2012.

36. Smith MA, Seibel NL, Altekruse SF, Ries LA, Melbert DL, O'Leary M, Smith FO, Reaman GH. (2010). Outcomes for children and adolescents with cancer: challenges for the twenty-first century. J Clin Oncol 28(15): 2625-2634

37. Norga Koenraad K. (2011). Pediatric oncology for the general pediatrician: introduction to the Educational series. Eur. J. Pediatr.

38. Smith MA, Seibel NL, Altekruse SF, Ries LA, Melbert DL, O'Leary M, Smith FO, Reaman GH. (2010). Outcomes for children and adolescents with cancer: challenges for the twenty-first century. J Clin Oncol 28(15): 2625-2634

39. Jones BL. (2012). The challenge of quality care for family caregivers in pediatric cancer care. Semin Oncol Nurs. 28: 213220

40. Jones B. (2006). Caregivers of children with cancer. J Human Behav Socl Environ 14: 221-240.

41. Kazak AE, Cant MC, Jensen MM, et al. (2003). Identifying psychosocial risk indicative of subsequent resource use in families of newly diagnosed pediatric oncology patients. J Clin Oncol 21: 3220-3225

42. Eden OB, Black I, MacKinlay GA, Emery AE. (1994). Communication with parents of children with cancer. Palliat Med 8(2): 105-114.

43. Ranmal R, Prictor M, Scott JT. (2008). Interventions for improving communication with children and adolescents about their cancer. Cochrane Database Syst Rev (4): CD002969.

44. Cadell S, Kennedy K, Hemsworth D. (2012). Informing social work practice through research with parent caregivers of a child with a life-limiting illness. J Soc Work End-of-Life Palliat Care, Special Issue on Pediatrics 8(4).

45. Fotiadou M, Barlow JH, Powell LA, et al. (2008). Optimism and psychological well-being among parents of children with cancer: an exploratory study. Psychooncology 17: 401-409.

46. Meyerson M, Gabriel S, Getz G (2010). Advances in understanding cancer genomes through second-generation sequencing. Nat Rev Genet 11(10): 685-696

47. Wolfe J, et al. (2008). Easing of suffering in children with cancer at the end of life: is care changing? J. Clin. Oncol. 26: 1717-1723.

48. Ferris FD, et al. (2009). Palliative cancer care a decade later: accomplishments, the need, next steps from the American Society of Clinical Oncology. J. Clin. Oncol. 27: 3052-3058.

49. Pui C-H, Gajjar AJ, Kane JR, Qaddoumi IA, Pappo AS. (2011). Challenging issues in pediatric oncology. Nat Rev Clin Oncol. 8: 540-549. 
50. Tomlinson D, Bartels U, Gammon J, et al. (2011). Chemotherapy versus supportive care alone in pediatric palliative care for cancer: comparing the preferences of parents and health care professionals. CMAJ : Canadian Medical Association Journal. 183(17): E1252-E1258.

51. Granek L, Barrera M, Shaheed J, Nicholas D, Beaune L, D'Agostino N, Bouffet E, Antle B. (2013). Trajectory of parental hope when a child has difficult-to-treat cancer: a prospective qualitative study.Psycho-oncology. 22(11): 2436-2444.

52. Duggleby W, Wright K. (2005). Transforming hope: how elderly palliative patients live with hope. Can J Nursing Research 37: 70-84.

53. Duggleby W. (2007). Enduring suffering: a grounded theory analysis of the pain experience of elderly hospice patients with cancer. Oncol Nurs Forum 27: 825-830.

54. Baker JN, Barfield R, Hinds PS, Kane JR. (2007). A process to facilitate decision making in pediatric stem cell transplantation: the individualized care planning and coordination model. Biol. Blood Marrow Transplant. 13: 245-254.

55. Baker JN, et al. (2008). Integration of palliative care practices into the ongoing care of children with cancer: individualized care planning and coordination. Pediatr. Clin. North Am. 55: 223-250.

56. Barrera M, D'Agostino N, Gammon J, et al. (2005). Healthrelated quality of life and enrollment in phase 1 trials in children with incurable cancer. Palliat Support Care 3: 191-6.

57. Tomlinson D, Bartels U, Hendershot E, et al. (2011). Factors affecting treatment choices in pediatric palliative care: comparing parents and health care professionals. Eur J Cancer Jun 11.

58. Shirado A1, Morita T, Akazawa T, Miyashita M, Sato K, Tsuneto S, Shima Y. (2013). Both maintaining hope and preparing for death: effects of physicians' and nurses' behaviors from bereaved family members' perspectives. J Pain Symptom Manage. May;45(5): 848-58

\section{Comment on this article:}

\section{$f(B)$ in $8+S P$}

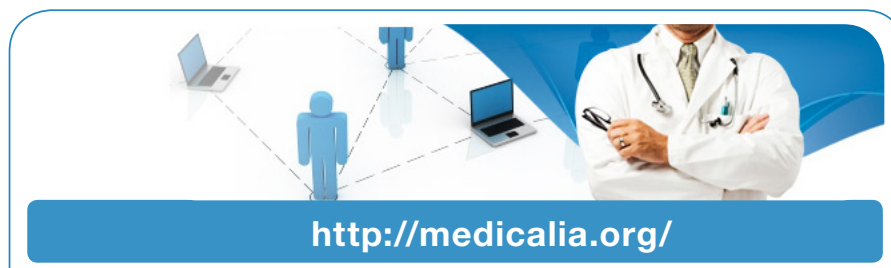

Where Doctors exchange clinical experiences, review their cases and share clinical knowledge. You can also access lots of medical publications for free. Join Now!

\section{Publish with iMedPub}

http://www.imed.pub

International Archives of Medicine is an open access journa publishing articles encompassing all aspects of medical science and clinical practice. IAM is considered a megajournal with independent sections on all areas of medicine. IAM is a really international journal with authors and board members from all around the world. The journal is widely indexed and classified Q1 in category Medicine. 